\title{
Statyba
}

\section{INFLUENCE OF COMPOSITION OF MORTAR MIXTURE ON STRENGTH AND DEFORMABILITY OF EXTERNAL WALLS}

\section{G. Marčiukaitis \& D. Zabulionis}

To cite this article: G. Marčiukaitis \& D. Zabulionis (2000) INFLUENCE OF COMPOSITION OF MORTAR MIXTURE ON STRENGTH AND DEFORMABILITY OF EXTERNAL WALLS, Statyba, 6:2, 76-81, DOI: $10.1080 / 13921525.2000 .10531569$

To link to this article: https://doi.org/10.1080/13921525.2000.10531569

曲 Published online: 26 Jul 2012.

Submit your article to this journal $₫$

Џ Article views: 84 


\title{
SKIEDINIO SUDE்TIES ITAKA IŠORINIŲ SIENOS SLUOKSNIŲ STIPRUMUI IR DEFORMAVIMUISI
}

\author{
G. Marčiukaitis, D. Zabulionis \\ Vilniaus Gedimino technikos universitetas
}

\section{Ivadas}

Pastato pagrindinè atitvara - siena turi atitikti ne tik stiprumo, pastovumo, bet ir pleišètumo reikalavimus. Todèl svarbias funkcijas atlieka sienos išoriniai sluoksniai. Pagrindinè sienų išorinių sluoksnių paskirtis yra: pirma, perimti dali apkrovos, antra, apsaugoti vidinius sluoksnius nuo atmosferos poveikio, trečia, suteikti pastatui ir jo išorei reikiamą architektūrinę išvaizdą.

Paskutines dvi funkcijas jie atlieka tik tuo atveju, jeigu išorinis apdailos sluoksnis nesupleišèjęs. Kai visi sienos sluoksniai standžiai sujungti, tai išoriniame apdailos sluoksnyje gali atsirasti tempimo itempių, dèl kurių atsiranda plyšiai.

Pagal galiojančius normatyvinius dokumentus ir kitus pasiūlymus [1-3], išorinių sluoksnių skaičiavimas (tam, kad neatsirastu plyšiu) atliekamas nuo išorinių apkrovu, kai visi sluoksniai standžiai sujungti ir yra padaryti iš lakštinių medžiagu (keraminių plytelių ir pan).

Tyrimai $[4,5]$ ir praktika rodo, kad dažnai supleišèja sieny lauko pusès išoriniai apdailos sluoksniai iš tinko: atšoka dažy sluoksniai su plonu tinko sluoksniu, o kartais supleišeja ir atšoka visas tinko sluoksnis. Taip atsitinka dèl to, kad projektuotojai ir statybininkai, neturèdami reikiamų duomenų, neịvertina vieno iš pagrindinių sluoksniuotujų konstrukcijų teorijos nurodymu - sluoksnių deformavimosi derinimo.

Daugelyje šalių, tarp jų ir mūsų šalyje, labiausiai paplitęs sienų išorinių sluoksnių apdailos būdas - tinkavimas. Sukurta daug tinko rūšių, tačiau dažniausiai naudojamas sudètinis cemento ir kalkių skiedinys.

Norint projektavimo stadijoje tiksliai ivertinti tinko ir kitu sluoksnių bendrą darbą, būtina žinoti tokias tinko fizikines-mechanines savybes kaip stiprị gniuždant, tempiant, gniuždymo ir tempimo ribines deformacijas, tamprumo modulị. Tačiau duomenų apie šias fizikines- -mechanines tinkavimui skirtų skiedinių savybes literatūroje beveik visai nèra.

Iki šiol apie tinko savybes dažniausiai buvo sprendžiama tik pagal jo markę, t. y. stipri gniuždant. Nèra duomenų apie kitu fizikinių-mechaninių savybiu priklausomybę nuo stiprio gniuždant ir kaip šios savybès kinta priklausomai nuo skiedinio sudèties. Todèl skaičiuojant sluoksniuotasias konstrukcijas su tinko sluoksniais negalima ivertinti deformacijų suderinamumo ir nustatyti tinko supleišèjimo galimybę arba jo išvengti. Šiame darbe pateikiami duomenys apie apdailos tinko sluoksnio stiprio ir deformacines savybes ir ju nustatymo bei parinkimo metodika.

\section{Tyrimo metodika}

Skiedinio kontroliniams mišiniams naudotas M 400 Akmenès cemento gamyklos gamybos portlandcementis (piltinè masẻ $1100 \mathrm{~kg} / \mathrm{m}^{3}$ ), gesintos kalkès, kvarcinis smèlis (kvarcinio smèlio granuliometrinę sudèti žr. 1 pav.).

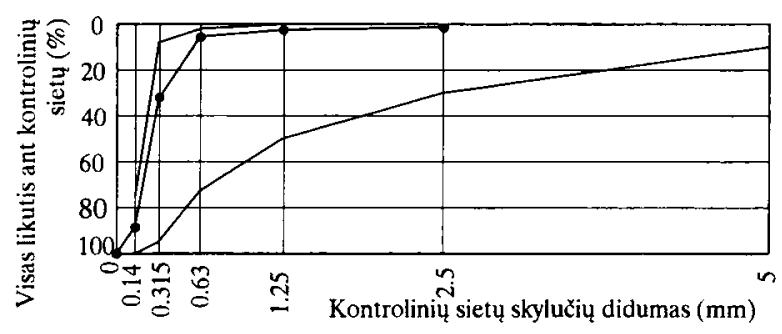

1 pav. Smèlio granuliometrinès sudèties pasiskirstymo grafikas

Fig 1. Diagram of distribution of granulometric composition of sand

Kaip matyti iš grafiko ( 1 pav.), smèlyje buvo didesnis smulkiosios frakcijos kiekis ( $<0,14 \mathrm{~mm})$. 
Siekiant ivertinti cemento ir kalkių skiedinio savybiu priklausomybę nuo jo sudeties, buvo atlikti eksperimentiniai tyrimai taikant matematinę eksperimentu planavimo metodiką $[6,7]$.

Atliktas nepilnutinis daugiafaktoris $3^{3}$ tipo eksperimentas. Eksperimento veiksniai buvo cemento, kalkių ir smèlio kiekiai tūrio dalimis. Vandens kiekis buvo toks, kad mišinys būtų tinkamas tinkuoti rankomis ir automatizuotai, t. y. skiedinio mišinio slankumas pagal kūgio ismigimo gyli visoms sudetims buvo $10 \mathrm{~cm} \pm 1 \mathrm{~cm}$.

Parenkant medžiagas, tiriant ju savybes ir atliekant pačius bandinius laikytasi Lietuvos Respublikos standartuc.

Pagal matematinio eksperimento planavimo metodiką buvo paruošta 15 skirtingos sudéties mišinių. Iš ju buvo gaminami kontroliniai bandiniai: 7,07 $\times 7,07 \times 7,07$ cm kubai, ir $4,0 \times 4,0 \times 16,0 \mathrm{~cm}$ prizmès, be to, ribinio ištįsimo deformacijoms ir tempimo stiprumui nustatyti buvo padarytos $7,07 \times 7,07 \times 28 \mathrm{~cm}$ matmenu prizmès. Visi bandiniai formose buvo laikomi 2 paras, normalioje temperatūroje, santykinei aplinkos drẻgmei esant $95 \% \pm 5 \%$. Išformuoti bandiniai laikyti tomis pačiomis sąlygomis. Jie bandyti po 28 pary.

Gniuždomo skiedinio stipris nustatytas bandant standartinius $7,07 \times 7,07 \times 7,07 \mathrm{~cm}$ kubus, kietejusius 28 paras normaliomis salygomis. Kontroliniai kubai pagaminti ir išbandyti pagal standarto LST 1413.6:1995 reikalavimus.

Tempiamo skiedinio stipris nustatytas lenkiant $7,07 \times 7,07 \times 28 \mathrm{~cm}$ prizmes. Bandymo metu buvo matuojamos skiedinio tempimo deformacijos.

Gniuždomo skiedinio deformacijos nustatytos gniuždant $4,0 \times 4,0 \times 16,0 \mathrm{~cm}$ prizmes.

\section{Eksperimentiniai tyrimo rezultatai ir tinko savybiy priklausomybès nuo sudèties aprašymas}

Bandymų rezultatai (žr. lentelę) buvo apdoroti taikant matematinès statistikos metodus, gaunant algebrines lygtis, rodančias ryši tarp skiedinio nagrinejjamu savybiu ir veiksnių (šiuo atveju cemento, kalkių, smèlio kiekio). Lygtyse atmesti nereikšmingi koeficientai, reikšmingumo lygis $\alpha=0,05$. Pateiktos algebrinès lygtys sprendžiamos su kintamaisiais $x_{1}, x_{2}, x_{3}$; čia $x_{1}$ - cemento, $x_{2}$ - kalkių, $x_{3}-$ smèlio kiekis tūrio dalimis, pvz., cementas : kalkès : smèlis $0,7: 0,5: 6$.

Pagal mūsų eksperimentų rezultatus gautose regresinèse lygtyse kintamieji gali kisti taip: $0,5 \leq x_{1} \leq 1,5$; $0,35 \leq x_{2} \leq 0,65 ; 4,5 \leq x_{3} \leq 6,5$.
Gauta, kad skiedinio stiprio gniuždant $R_{m, c}(\mathrm{MPa})$ priklausomybè nuo nurodytų veiksnių yra tokia:

$$
\begin{aligned}
& R_{m, c}=10,61+16,33 \cdot x_{1}-5,44 \cdot x_{3}+ \\
& +0,545 \cdot x_{3}^{2}-1,79 \cdot x_{1} x_{3} .
\end{aligned}
$$

Prizminis skiedinio stipris gniuždant $R_{m, p}(\mathrm{MPa})$ nuo minetų veiksniu priklauso taip:

$R_{m, p}=-4,69+14,29 \cdot x_{1}+0,42 \cdot x_{3}-1,57 \cdot x_{1} \cdot x_{3}$.

Skiedinio stipris lenkiant $R_{m, t}(\mathrm{MPa})$ arba stipris tempiant yra:

$$
R_{m . t}=1,17+0,85 \cdot x_{1}-0,48 \cdot x_{2}-1,57 \cdot x_{3} .
$$

Svarbios tinko skiedinio charakteristikos yra ribinès gniuždymo ir tempimo deformacijos, taip pat tamprumo modulis. Tačiau apie tai duomenų literatūroje beveik nesutinkama.

Bandymai parodè, kad skiedinio ribines gniuždymo deformacijas $\varepsilon_{m, c, u}\left(10^{5}\right)$ priklausomai nuo jo sudeties galima nustatyti pagal tokią lygti:

$$
\begin{aligned}
& \varepsilon_{m, c, u}=-1065,822-79 \cdot x_{1}-417,122 \cdot x_{2}+ \\
& +485,526 \cdot x_{3}+49,86 \cdot x_{1}^{2}+452,222 \cdot x_{2}^{2}- \\
& -45,625 \cdot x_{3}^{2}+48,227 \cdot x_{1} \cdot x_{2},
\end{aligned}
$$

o tamprumo moduli $E_{m}(\mathrm{MPa})$ :

$$
\begin{aligned}
& E_{m}=-5873,67+17212,67 \cdot x_{1}+5453,33 \cdot x_{2}+ \\
& +472 \cdot x_{3}-9533,33 \cdot x_{1} \cdot x_{2}-1280 \cdot x_{1} \cdot x_{3} .
\end{aligned}
$$

$(1,2,3,5)$ lygtys adekvačios, t. y. skaičiuojamoji Fišerio kriterijaus reikšmè $F_{p}$ mažesnè už kritinę Fišerio kriterijaus reikšmę $F$. Reikšmingumo lygis $\alpha=0,05$.

(4) lygtis yra neadekvati $F_{p}=33,609>F=19,2$, kai $\alpha=0,05$. Tačiau šis neadekvatumas gali būti sukeltas mažos nulinio lygio dispersijos $S_{0}^{2}=18,901$, o adekvatumo dispersija yra didelè $S_{a d}^{2}=635,248$. Palyginti su $\varepsilon_{s, h, c}$ nulinio lygio dispersija, $S_{0}^{2}=197,613, S_{a d}^{2}=471,751$.

Kai reikšmingumo lygis imamas $\alpha=0,01$, tai kritine $F$ kriterijaus reikšmė padidèja iki 99 , todèl galima teigti, kad reikšmingumo lygiui $\alpha=0,01 \varepsilon_{m, c, u}$ lygtis yra adekvati [8].

\section{Tyrimo rezultatų analizè}

Kaip matyti iš (1) lygties ir 2 pav., egzistuoja beveik tiesinè priklausomybè tarp cemento ir smèlio santykio $\left(C / S_{m}\right)$ ir stiprio gniuždant $\left(R_{m, c}\right)$. 
Tinko skiedinio fizikinès-mechanines savybès

Physical and mechanical properties of mortar

\begin{tabular}{|c|c|c|c|c|c|c|}
\hline 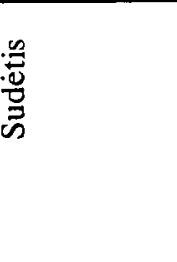 & 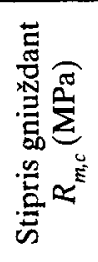 & 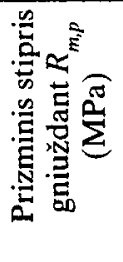 & 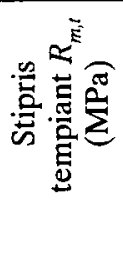 & 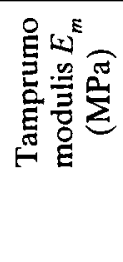 & 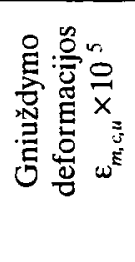 & 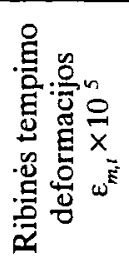 \\
\hline 2 & 3 & 4 & 5 & 6 & 7 & 8 \\
\hline $1: 0.23: 3,00$ & 10,20 & 9,39 & 1,53 & 10400 & 123 & 22 \\
\hline $1: 0,70: 9,00$ & 1,50 & 1,36 & 0,7 & 2380 & 85 & 21 \\
\hline $1: 0,43: 3,00$ & 9,50 & 7,83 & 1,29 & 8050 & 144 & 25 \\
\hline $1: 1,30: 9,00$ & 1,10 & 1,49 & 0,6 & 2610 & 91 & - \\
\hline $1: 0,23: 4,33$ & 5,70 & 5,25 & 1,20 & 7740 & 86 & - \\
\hline $1: 0,70: 13,00$ & 0,55 & 0,70 & 0,32 & 2000 & 53 & - \\
\hline $1: 0,43: 4,33$ & 5,40 & 4,08 & 1,15 & 5070 & 114 & - \\
\hline $1: 1,30: 13,00$ & 0,54 & 0,55 & 0,09 & 2470 & 68 & - \\
\hline $1: 0,33: 3,67$ & 6,15 & 6,85 & 1,22 & 7130 & 185 & - \\
\hline $1: 1,00: 11,00$ & 0,9 & 1,09 & 0,42 & 1900 & 132 & 21 \\
\hline $1: 0,35: 5,50$ & 4 & 3,17 & 1,01 & 5720 & 128 & 16 \\
\hline $1: 0,65: 5,50$ & 3,16 & 3,22 & 0,91 & 3920 & 184 & 25 \\
\hline $1: 0,50: 4,50$ & 5,2 & 4,59 & 1,07 & 6470 & 121 & 17 \\
\hline $1: 0,50: 6,50$ & 2,9 & 2,59 & 0,86 & 4550 & 79 & - \\
\hline $1: 0,50: 5,50$ & 4,1 & 3,12 & 0,90 & 4830 & 94,7 & 20 \\
\hline
\end{tabular}

Šie duomenys taip pat rodo, kad kalkès skiedinio stipriui gniuždant po 28 parų kietéjimo laikotarpio ịtakos neturi. Tačiau kalkes pagerina skiedinio technologines savybes ir laikui begant, nors ir letai, tačiau jos karbonatizuojasi ir didina tinko stipri gniuždant $[2,9]$.

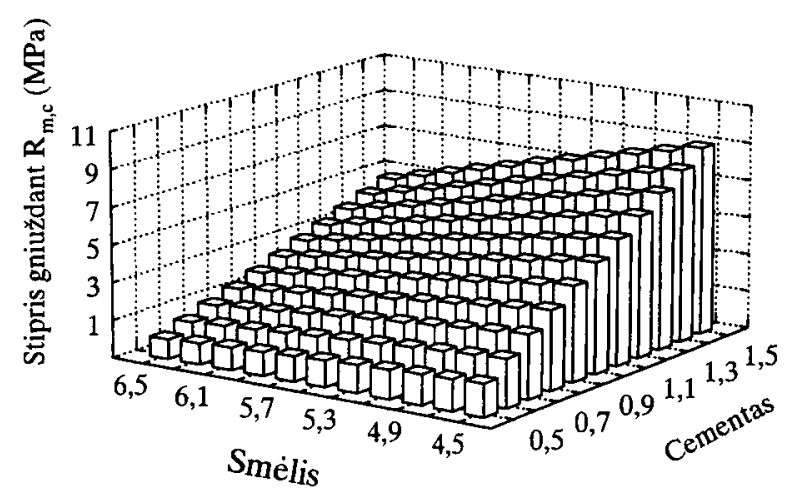

2 pav. Skiedinio stiprio gniuždant priklausomybè nuo cemento ir smelio kiekio türio dalimis

Fig 2. Relationship between compressive strength of mortar and volume parts of cement and sand

Skaičiuojant tinko sluoksnio darbą kartu su kitais sluoksniais svarbu žinoti prizmini stiprị $R_{m, p}$. Iš (2) lygties ir 3 pav. matyti, kad gniuždomo skiedinio prizminis stipris irgi priklauso tik nuo $C / S_{m}$ santykio. Kalkių kiekis skiedinio stipriui gniuždant taip pat beveik neturi jokios itakos.

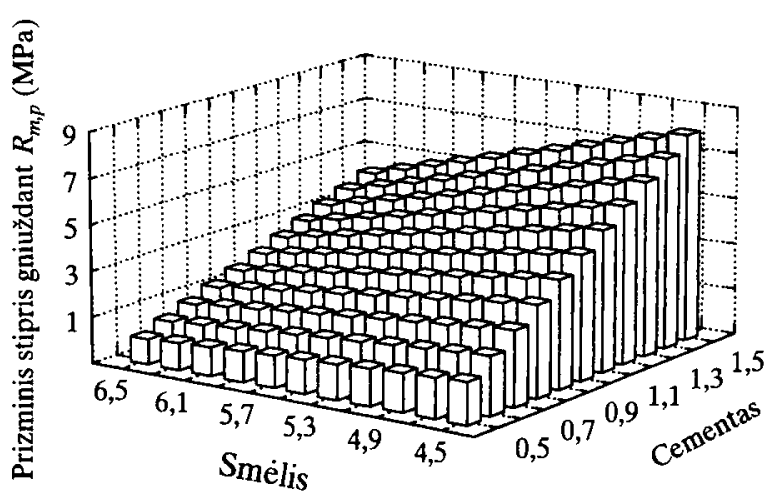

3 pav. Skiedinio prizminio stiprio priklausomybès nuo smèlio ir cemento kiekio tūrio dalimis

Fig 3. Relationship between compressive prism strength of mortar and volume parts of cement and sand

Palyginus 1 ir 2 lygtis, taip pat 3 ir 4 paveiksla matyti, kad kubelinio ir prizminio stiprio priklausomybès panašios. Palyginus skiedinio $R_{m, c}$ ir $R_{m, p}$ gauta, kad vidutiniškai $R_{m, p}=0,83 R_{m, c}$. Panašios priklausomybès tarp betono kubelinio $R$ ir prizminio stiprio $R_{b}$ yra gautos daugelio ịvairių autorių. 
Norint užtikrinti tinko sluoksnio atsparuma pleišèjimui veikiant bet kokiems poveikiams, būtina žinoti jo stiprumą tempiant. Tačiau apie šią tinko savybę duomenu trūksta. Taikant (3) lygti ir naudojantis 4 pav. duomenimis galima parinkti tinko skiedinio sudeti, leidžiančia gauti norimą tinko stiprị tempiant. (3) lygties analizè rodo, kad tarp stiprio tempiant ir ivairių mišinio sudečiu yra tiesinè priklauomybè. Gautı rezultatu analizè rodo, kad didejant smèlio ir kalkiu kiekiui skiedinio stipris tempiant mažèja, o didejant cemento kiekiui $R_{m, t}$ didejja. Palyginus gniuždomo skiedinio stiprio $R_{m, c}$ reikšmes su tempiamo skiedinio stiprio $R_{m, t}$ reikšmèmis gauta, kad, $R_{m, c} / R_{m, r}=0,6 \div 6$.

Didejant stipriui gniuždant stipris tempiant santykinai mažeja ir atvirkščiai.

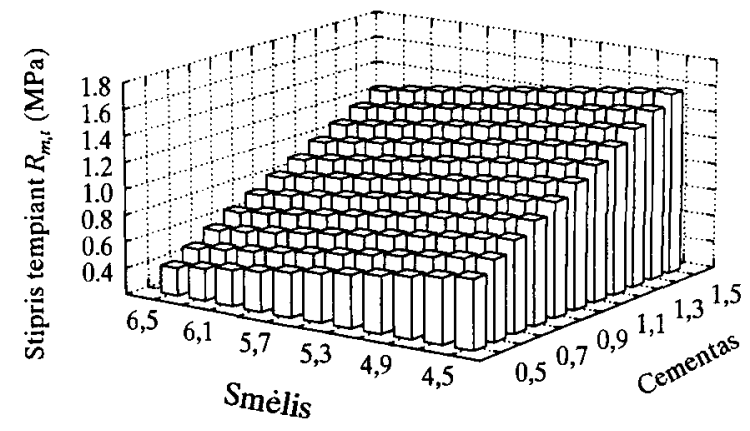

4 pav. Skiedinio stiprio tempiant priklausomybè nuo cemento, kalkių ir smèlio kiekio tūrio dalimis, kai kalkių kiekis tūrio dalimis 0,65

Fig 4. Relationship between tensile strength of mortar and volume parts of cement, sand and lime, when volume part of lime is 0.65

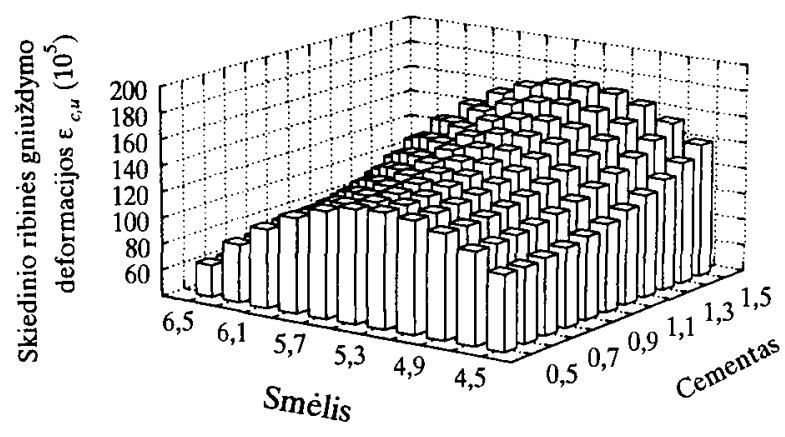

5 pav. Skiedinio ribinių gniuždyno deformacijų priklausomybè nuo cemento, kalkiụ ir smélio kiekio tūrio dalimis, kai kalkių kiekis tūrio dalimis 0,35

Fig 5. Relationship between tensile limit strain of mortar and volume parts of cement, sand and lime, when volume part of lime is 0.35
Kaip buvo minèta, norint užtikrinti tinko sluoksnio bendrą darbą su laikančiuoju sluoksniu, reikia parinkti tokị tinką, kad būtų išlaikytas sluoksnių deformacijų derinamumo principas. Todèl būtina žinoti gniuždymo ir tempimo deformacijas. Literatūroje sutinkami duomenys apie deformavimosi savybes [9-11] yra pateikiami tik tam tikros sudèties skiediniams ir nèra platesnès jų analizès. Be to, literatūroje sutinkami duomenys daugiausia yra apie mūrijimo darbų skiedinius, kuriu sudetys (ypač smèlio granuliometrinè sudètis) ir technologinès savybès yra skirtingos.

Atlikti bandymai ir (4) lygties bei 5 paveikslo duomenu analizè rodo, kad gniuždomo tinko deformacinèms savybèms turi itakos visi trys veiksniai: cementas, kalkès, smèlis. Didžiausią ịtaką turi $C / S_{m}$ santykis. Bandymu rezultatai ir (4) lygties analizè rodo, kad kalkès turi teigiamą itaką ribiniu gniuždymo deformacijų dydžiui.

Tačiau ši analizè taip pat parodè, kad deformacinèms savybèms didelę itaką turi smèlio, kaip vieno iš pagrindiniu komponentu̧ kiekis (5 pav.). Pasiekus tam tikrą optimalią ribą, jo kiekio didinimas arba mažinimas joms daro neigiamą itaka.

Kaip matyti iš 6 pav. pavaizduotos $\sigma-\varepsilon$ priklausomybių kreivès, gniuždant tinkas deformuojasi tampriai plastiškai. Didèjant stipriui gniuždant tinko tampriojo deformavimosi riba taip pat dideja.

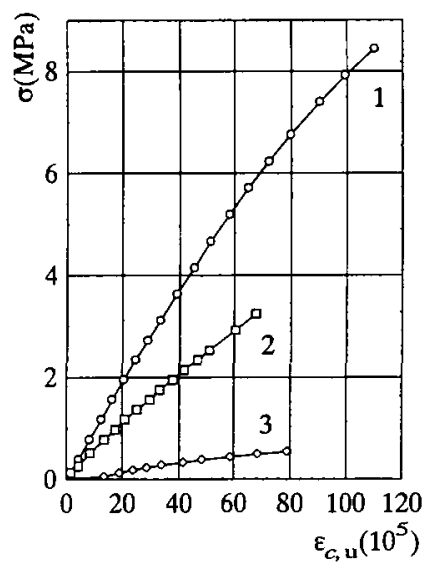

6 pav. Deformaciju kitimas gniuždant: $1-1: 0,23: 3$ serija $R_{m, p}=8,44 \mathrm{MPa}, 2-1: 0,5: 5,5$ serija $R_{m, p}=3,25 \mathrm{MPa}$, $3-1: 1,3: 13$ serija $R_{m, p}=0,54 \mathrm{MPa}$

Fig 6. Variation of compression strain: $1-1: 0.23: 3 \mathrm{se}-$ ries $R_{m, p}=8.44 \mathrm{MPa}, 2-1: 0.5: 5,5$ series $R_{m, p}=3.25 \mathrm{MPa}$, $3-1: 1,3: 13$ series $R_{m, p}=0.54 \mathrm{MPa}$ 
Nustatant tinko sluoksnio atspanumą pleišèjimui, jo bendrą deformavimassi kartu su kitais sluoksniais veikiant temperatūros, drègmès, pokyčiams ir kitiems poveikiams, būtina žinoti ribines deformacijas tempiant bei deformavimosi pobūdi.

Kaip matyti iš 7 pav., skiedinio tempimo deformacijų priklausomybè nuo itempiu taip pat yra kreivoji. Ribinès tempimo deformacijos yra pateiktos lentelèje. Šie duomenys rodo, kad jos mažiau priklauso nuo skiedinio stiprumo gniuždant ir jo sudèties. Gniuždymo deformacijos skiriasi priklausomai nuo stiprumo iki 2 kartu, tuo tarpu tempimo ribinès deformacijos - iki 1,5 karto.

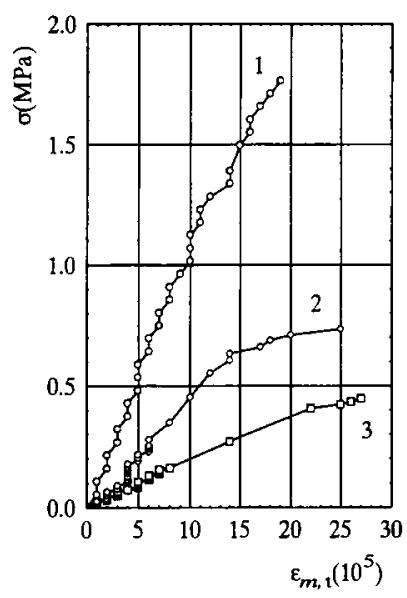

7 pav. Lenkiamų skiedinio prizmių tempimo deformacijų priklausomybè nuo ittempimų: $1-1: 0,23: 3$ serija $R_{m, \digamma}=1,77 \mathrm{MPa}, 2-1: 0,5: 5,5$ serija $R_{m, 5}=0,758 \mathrm{MPa}, 3-$ $1: 1: 11$ serija $R_{m, r}=0,456 \mathrm{MPa}$

Fig 7. Relationship between stress and strain in prism under bending mode of mortar: $1-1: 0.23: 3, R_{m, r}=1.77 \mathrm{MPa}$, 2 - 1:0.5:5.5, $R_{m,}=0.758 \mathrm{MPa}, 3-1: 1: 11, R_{m, r}=0.456$ $\mathrm{MPa}$

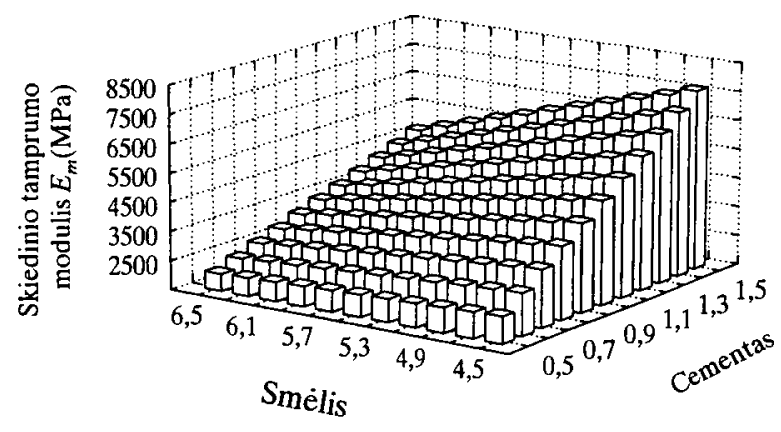

8 pav. Skiedinio tamprumo modulio priklausomybès nuo kalkių, smelio ir cemento kiekio tūrio dalimis, kai kalkiụ kiekis tūrio dalimis 0,35

Fig 8. Relationship between elasticity modulus of mortar and its volume parts of cement, lime and sand (volume parts of lime is 0.35 )
Skiedinio, kaip ir kitų statybinių medžiagų, deformacines savybes veikiant apkrovai charakterizuoja deformaciju modulis. Pagal išmatuotas deformacijas in $\sigma-\varepsilon$ priklausomybes buvo nustatytas tinko deformaciju modulis, kurio reikšmès pateiktos lentelèje.

Bandymo ir skaiciavimo rezultaty ( 8 pav.) analizè rodo, kad tamprumo moduliui didžiausią itaką turi $\mathrm{C} / S_{m}$ santykis. Esant silpnam skiediniui $\left(R_{m, r}=0,5 \mathrm{MPa}\right)$, tamprumo modulis labiau priklauso nuo kalkiu kiekio mišinyje. Tai matyti iš (5) lygties.

\section{Išvados}

1. Tinko fizikinès-mechaninès savybès priklauso nuo jo skiedinio sudèties. Daugiausia itakos visoms tinko savybèms turi cemento kiekis ir jo santykis su smèliu. Kalkiu kiekis turi įtakos esant mažesniam cemento kiekiui.

2. Tinko deformacinems savybèms didelès ịtakos turi mišinio komponentų grūdelių granuliometrinè sudètis ir jų santykis.

3. Pasiūlytos regresijos lygtys, pagal kurias skiedinio tinkui galima parinkti sudéti pasižyminčią tam tikromis fizikinèmis-mechaninèmis savybèmis.

4. Skiedinio stipris gniuždant neatsitiktinai priklauso tik nuo $C / S_{m}$ santykio. Pagal 1 ir 2 lygtis $R_{m, c}$ priklausomybè nuo kalkiu atsitiktinè. Tai priklauso nuo mišinio sudèties ir tarpy tarp smèlio grūdelių užpildymo rišančiosios medžiagos smulkesniais grūdeliais.

5. Skiedinio deformacinès savybès, tamprumo modulis, stipris tempiant neatsitiktinai priklauso nuo visu veiksnių, t. y. nuo cemento, kalkių ir smèlio kiekio.

\section{Literatūra}

1. СНиП II-22-81. Строительные нормы и правила. Нормы проектирования. Каменные и армокаменные конструкции. Москва: Стройиздат, 1983. 39 с.

2. A. I. Hendry. Structural Masonrry. London. Macmillan Education, Ltd. 1990. 220 p.

3. Eurocode 6. - Design of Masonry Structures. - Part 1-1: General Rules for Buildings. Rules for Reinforced an Unreinforced Masonry. Brussels, 1994. $10 \mathrm{p}$.

4. G. Marčiukaitis. Technologiniu faktoriu itaka sluoksniuotujų sienų išorinių sluoksnių supleišejimui // 5-osios tarptautinès konferencijos „Naujos statybinès medžiagos, konstrukcijos ir technologijos", ivykusios Viniuje $1997 \mathrm{~m}$. gegužès 21-24 d., straipsniai, IV t., Vilnius: Technika, 1997, p. $172-177$.

5. G. Marciukaitis. The influence of sudden increase in temperature and humidity on stress-strain states in exterior finishing layers of multileaf walls with flexible ties // Statyba, IV t., Nr. 3, Vilnius: Technika, 1998, p. 219-226. 
6. Руководство по подбору составов тяжелого бетона. Москва: Стройиздат, 1979. 101 с.

7. Ю. П. Адлер. Введение в планирование эксперимента. Москва: Металлургия, 1969. 155 с.

8. J. Kruopis. Matematine statistika. Vilnius: Mokslas, 1993. $415 \mathrm{p}$.

9. A. Rozenbliumas. Mūrinès konstrukcijos. Vilnius, 1956. $443 \mathrm{p}$.

10. С. В. Поляков. Длительное сжатие кирпичной кладки. Научное сообщение. Вып. 11. Москва: Стройиздат, 1959. $181 \mathrm{c}$

11. C. T. Grim. Strength and Related Properties of brick Masonry // Juournal of structural Division, Vol 101, No ST1, 1975, p. 117-232. STDEV.

Iteikta 20000403

\section{INFLUENCE OF COMPOSITION OF MORTAR MIXTURE ON STRENGTH AND DEFORMABILITY} OF EXTERNAL WALLS

\section{G. Marčiukaitis, D. Zabulionis}

\section{Su m mary}

The basic element of building, wall, must satisfty not only requirements for strength, stability, but also for cracking. Experiments and practice show that in many cases external decoration layers of external walls are cracked. It is because designers and builders do not take into consideration one of the basic conditions of the theory of layers - to satisfy compatibility of deformations of layers. Therefore it is necessary to know physical and mechanical properties of plasters such as strength limits of compressive and tensile strains and modulus of elasticity. In this paper, data and recommendations about strength and deformation properties of plaster are given, as well as regressive equations by which it is possible to choose the composition of composite cement-lime-sand mortar recording the following parameters: compressive and tensile strength, limit strain, modulus of elasticity. Analysis of experimental data shows that the compressive and tensile strength of mortar and modulus of elasticity mainly depend on the ratio cement/sand. Limit deformations depend on all 3 factors: cement, lime and sand.

Gediminas MARČIUKAITIS. Professor, Doctor Habil. Head of Dept of Reinforced Concrete and Masonry Structures. Vilnius Gediminas Technical University (VGTU), Sauletekio al. 11, LT-2040 Vilnius, Lithuania.

$\mathrm{PhD}$ (1963). Research visit to the University of Illinois (1969). Doctor Habil (1980) at Moscow Civil Engineering University. Professor (1982). Author and co-author of 5 monographs, 3 text-books and about 280 scientific articles. Research interests: mechanics of reinforced concrete, masonry and layered structures, new composite materials, investigation and renovation of buildings.

Darius ZABULIONIS. PhD student. Dept of Reinforced Concrete and Masonry Structures. Vilnius Gediminas Technical University (VGTU), Sauletekio al. 11, LT-2040 Vilnius, Lithuania.

BSc (1996) and MSc (1998) in Civil Engineering at VGTU. Co-author of 1 research paper. Research interests: masonry and layered structures. 